\title{
Early and medium-term results for repair of Ebstein anomaly
}

Jonathan M. Chen, MD

Ralph S. Mosca, MDa

Karen Altmann, $M D^{\mathrm{b}}$

Beth F. Printz, $M D^{\mathrm{b}}$

Kimara Targoff, $M D^{b}$

Pamela A. Mazzeo, BA ${ }^{\text {a }}$

Jan M. Quaegebeur, MD
From the Divisions of Pediatric Cardiac Surgery $^{\mathrm{a}}$ and Pediatric Cardiology, ${ }^{\mathrm{b}}$ Children's Hospital of New York, Columbia University College of Physicians and Surgeons, New York, NY.

Read at the Eighty-third Annual Meeting of The American Association for Thoracic Surgery, Boston, Mass, May 4-7, 2003.

Received for publication May 2, 2003; revisions requested Oct 23, 2003; accepted for publication Nov 4, 2003.

Address for reprints: Jonathan M. Chen, MD, Pediatric Cardiac Surgery, 3959 Broadway, Suite 2-273, New York, NY 10032 (E-mail: jmc23@columbia.edu).

J Thorac Cardiovasc Surg 2004;127:990-9

$0022-5223 / \$ 30.00$

Copyright $\odot 2004$ by The American Association for Thoracic Surgery

doi:10.1016/j.jtcvs.2003.11.037
Objectives: We evaluated the early and medium-term single-center results for primary repair of Ebstein anomaly in both adults and children.

Methods: The records were reviewed of patients undergoing repair of Ebstein anomaly at the Children's Hospital of New York from September 1990 to September 2002. Functional, demographic, and echocardiographic parameters were studied both preoperatively and postoperatively, along with functional status and adverse events. The repair technique involved vertical plication of the atrialized ventricle and valve leaflet reimplantation after clockwise rotation.

Results: A total of 25 patients (19 children and 6 adults) underwent repair. The average age was $14.2 \pm 15.9$ years, and the average follow-up was $4.1 \pm 3.4$ years. Three patients required reoperation for right ventricular overload (1 child) and progressive, severe tricuspid regurgitation ( 2 adults); both adults received tricuspid valve replacements, one at 4 years and the other at 8 years post-repair. Three patients had radiofrequency ablation procedures performed intraoperatively. Ten patients $(40 \%)$ had moderate-to-severe tricuspid regurgitation perioperatively. However, 18 children (95\%) and 5 adults (83\%) demonstrated significant improvement in exercise capacity late postoperatively. Two children died suddenly 11 months and 4 years after repair.

Discussion: Ebstein repair has good functional outcomes in children despite residual tricuspid regurgitation, likely because of reduction in right ventricular volume loading and relative annular and ventricular plasticity. Adult patients did not demonstrate the same durability of valve repair and frequently required tricuspid valve replacement. Intraoperative radiofrequency ablation represents an important adjunctive treatment for intractable arrhythmias, which may now represent relative indications for operative intervention.

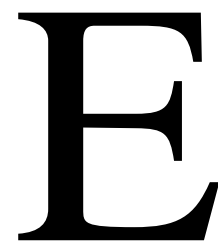

bstein anomaly of the tricuspid valve is an unusual congenital cardiac lesion notable for its extremely variable natural history. The clinical expression of the disease may become manifest at any age and encompasses the spectrum of severity from nearly uniform mortality if left untreated in the symptomatic neonate to long-term survival in some adults with and without repair. ${ }^{1-4}$ In infants and children, right-to-left shunting at the atrial level can result in significant cyanosis, whereas in older patients, symptoms typically represent the effects of ongoing tricuspid regurgitation and right ventricular dysfunction. At any age, rhythm abnormalities in patients with Ebstein anomaly, either the result of protracted atrial 
distension or abnormal myocardial substrate, remain the cause of significant morbidity and sudden death. ${ }^{5-7}$

Until relatively recently, the results of surgical correction for this lesion were limited, and thus surgery had been reserved only for those with increasing disability. However, during the past 2 decades, several innovative techniques have been promoted as alternatives to valve replacement for repair of Ebstein anomaly, most of which involve tricuspid valve restoration and some degree of plication of the atrialized ventricle. ${ }^{8-17}$ We previously described our reparative technique with promising early results ${ }^{17}$ and undertook the current study to evaluate further the outcomes of our patients who underwent repair of Ebstein anomaly during the past 12 years.

\section{Methods}

We reviewed the records of all patients who underwent repair of Ebstein anomaly from September 1990 to September 2002 at the Children's Hospital of New York. Functional and demographic parameters were evaluated including age, gender, indication for surgical correction, associated lesions, preoperative radiographic cardiothoracic ratio, exercise testing (when available), presence of preoperative arrhythmia, and previous procedures.

Preoperative and postoperative echocardiograms were analyzed by 2 blinded echocardiographers according to a modified grading scale ("Ebstein Severity Scale") as previously described by Carpentier and colleagues and Quaegebeur and colleagues: ${ }^{9,17}$ grade A, mobile anterior tricuspid valve leaflet with a small contractile atrialized chamber; grade B, large, noncontractile atrialized chamber but mobile anterior leaflet; grade $\mathrm{C}$, tethering of the distal attachments of the anterior leaflet and a large noncontractile atrialized chamber; and grade $\mathrm{D}$, leaflet tissue forming a continuous sac adherent to the right ventricle. The current echocardiographic analysis also included parameters of (1) right and left ventricular function, (2) severity of tricuspid regurgitation, and (3) degree of anterior tricuspid leaflet mobility. In addition, in postoperative studies, the level of displacement of the tricuspid apparatus was assessed.

The early and late postoperative functional status was correlated with these findings, as were adverse events, including atrial arrhythmias, heart block, need for adjunctive procedures, need for tricuspid valve replacement, and all-cause mortality. All patients were evaluated clinically over a time period extending from the perioperative period to as long as 10.9 years postoperatively. Routine transthoracic echocardiography was obtained before hospital discharge and graded by the system described. Additional transthoracic echocardiography and exercise tests were obtained later postoperatively at the discretion of the referring cardiologist.

\section{Valve Repair Technique}

After institution of cardiopulmonary bypass with moderate hypothermia $\left(28^{\circ} \mathrm{C}\right)$, the aorta is crossclamped, and cardioplegic arrest is induced. The right atrium is opened parallel to the atrioventricular groove, and the tricuspid valve is inspected. The anterior leaflet (and posterior leaflet when not diminutive) is detached from the tricuspid annulus, starting at the anteroseptal commissure (leaving the attachment at the level of the commissure untouched)

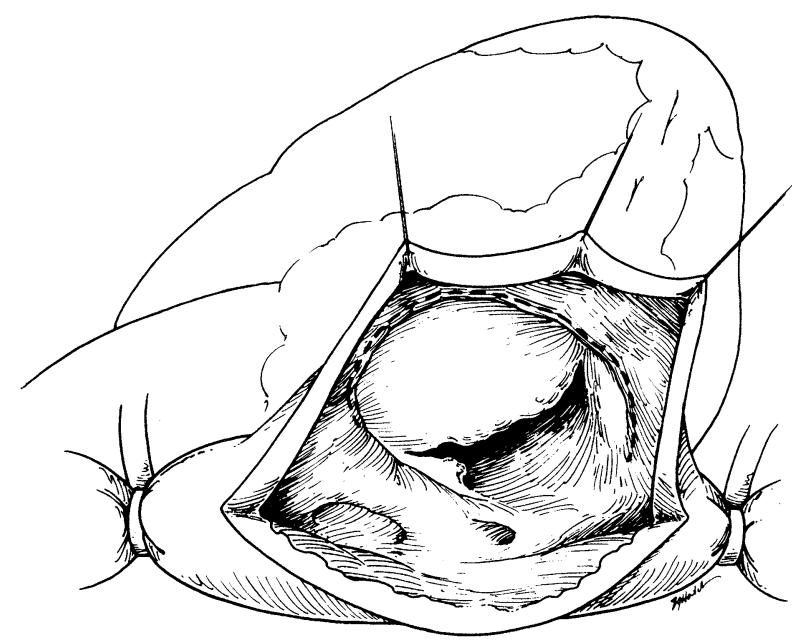

Figure 1. Detachment of the anterior leaflet from the tricuspid annulus. Reprinted from the Journal of the American College of Cardiology, Vol 17, Quaegebeur JM, Sreeram N, Fraser AG, Bogers AJ, Stumper OF, Hess J, et al. Surgery for Ebstein's anomaly: the clinical and echocardiographic evaluation of a new technique, p 722-8, copyright 1991, with permission from "The American College of Cardiology Foundation."

and proceeding along the annulus (Figure 1). Further mobilization of the detached leaflet(s) may require both additional division of abnormal fibrous bands of tissue (trabeculations) extending between the leaflets and the ventricular wall and dissection of the papillary muscle attachments from the ventricular wall as far as the apical portion of the right ventricle. Care must be taken to maintain the valve attachments to the free edge to preserve valve function and prevent flail movement (Figure 2).

The atrialized right ventricle is then plicated longitudinally with continuous 5-0 Prolene suture (Ethicon, Inc, Somerville, NJ) in a method modified from Carpentier and coworkers. ${ }^{9}$ The area of tissue that is plicated forms a "wedge," the boundaries of which are a line that runs from the apex of the atrialized portion to the coronary sinus, including the septal leaflet attachments, and a second line that starts at a similar point and ascends along the diaphragmatic endocardial surface of the atrialized chamber (Figure 3). Thus, the original attachments of the posterior leaflet are included in the plicated tissue. Of note, neither the septal leaflet nor its remnants are included in the repair. Attention must be paid so that neither suture line is transmural to avoid injury to the posterior descending artery. The plication of the atrialized ventricle is specifically performed caudal to the coronary sinus to avoid fibers of the conduction system. In 2 cases, the right atrial tissue itself was so redundant as to require atrial excision.

Finally, the anterior and posterior (where applicable) leaflets are reattached to the new tricuspid annulus with a moderate clockwise rotation (Figure 4). Every effort is made to bring the leading rotated edge of the leaflet to adjoin the edge of the septal leaflet tissue. Although no prosthetic rings are used in the repair, in 3 instances, a single, pledgeted annuloplasty suture was further inserted to reinforce the repair and downsize the tricuspid annulus. In 1 additional patient, artificial chords composed of polytetrafluo- 


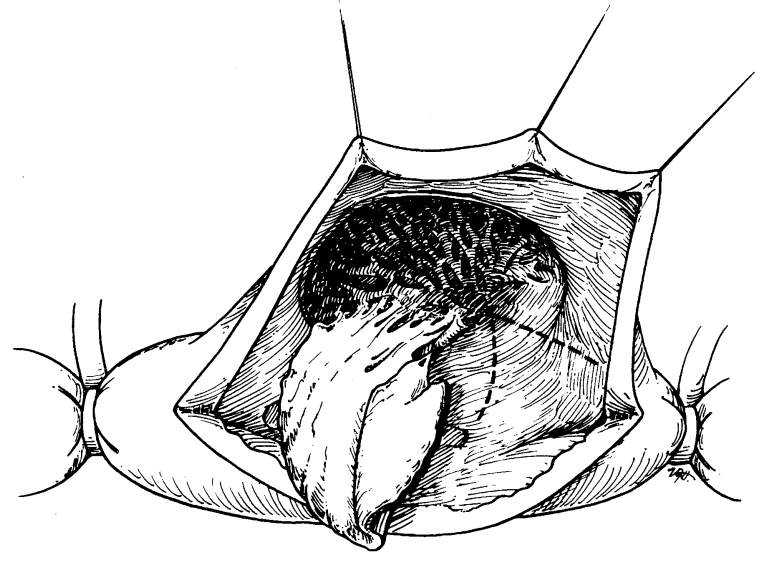

Figure 2. Leaflet fully mobilized. Area of atrialized ventricle to be plicated noted by dotted lines. Reprinted from the Journal of the American College of Cardiology, Vol 17, Quaegebeur JM, Sreeram N, Fraser AG, Bogers AJ, Stumper OF, Hess J, et al. Surgery for Ebstein's anomaly: the clinical and echocardiographic evaluation of a new technique, p 722-8, copyright 1991, with permission from "The American College of Cardiology Foundation."

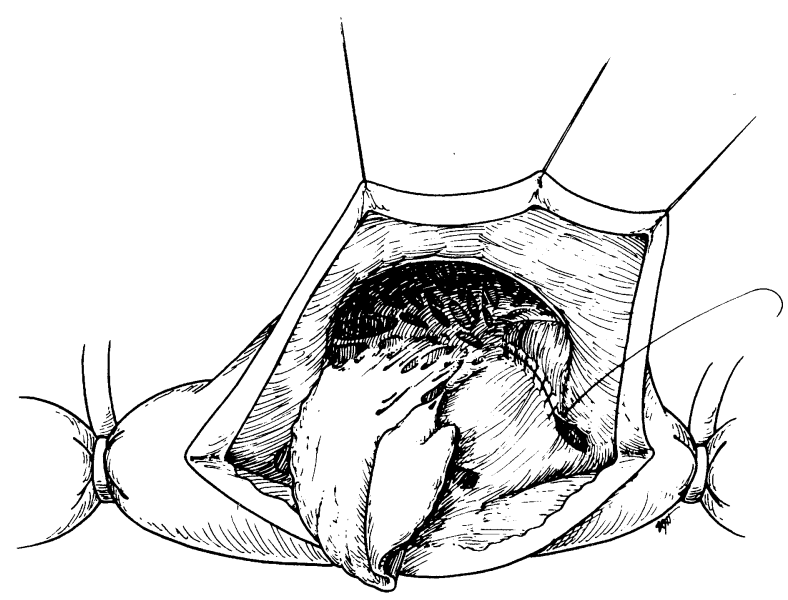

Figure 3. Plication of the atrialized ventricle. Reprinted from the Journal of the American College of Cardiology, Vol 17, Quaegebeur JM, Sreeram N, Fraser AG, Bogers AJ, Stumper OF, Hess J, et al. Surgery for Ebstein's anomaly: the clinical and echocardiographic evaluation of a new technique, p 722-8, copyright 1991, with permission from "The American College of Cardiology Foundation."

roethylene (Gore-Tex, W. L. Gore \& Associates, Flagstaff, Ariz) suture were used to maintain competency of the tricuspid valve.

The competence of the tricuspid valve is then tested with injection of saline solution into the right ventricle during cardiopulmonary bypass, and additional procedures are performed (eg, closure of atrial septal defect and radiofrequency ablation). The right atrium is closed, the patient is weaned off cardiopulmonary bypass support, and the valve is again assessed by intraoperative transesophageal echocardiogram.

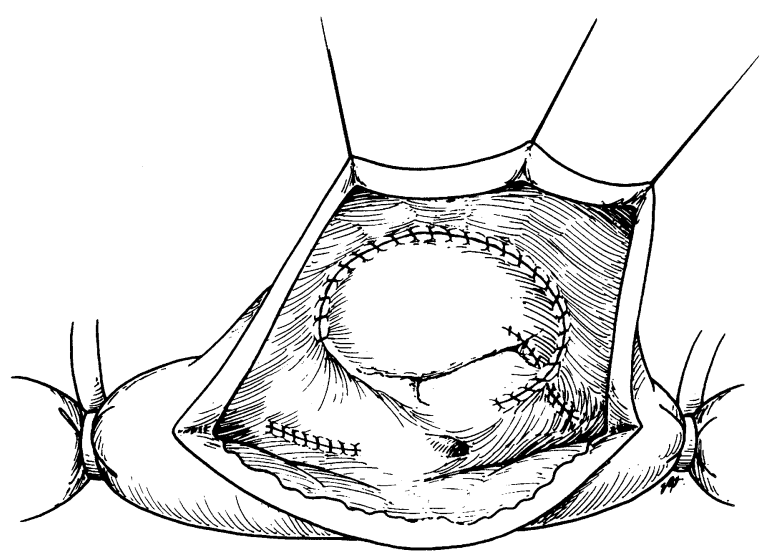

Figure 4. Post-repair with closure of atrial septal defect. Reprinted from the Journal of the American College of Cardiology, Vol 17, Quaegebeur JM, Sreeram N, Fraser AG, Bogers AJ, Stumper OF, Hess J, et al. Surgery for Ebstein's anomaly: the clinical and echocardiographic evaluation of a new technique, $p$ 722-8, copyright 1991, with permission from "The American College of Cardiology Foundation."

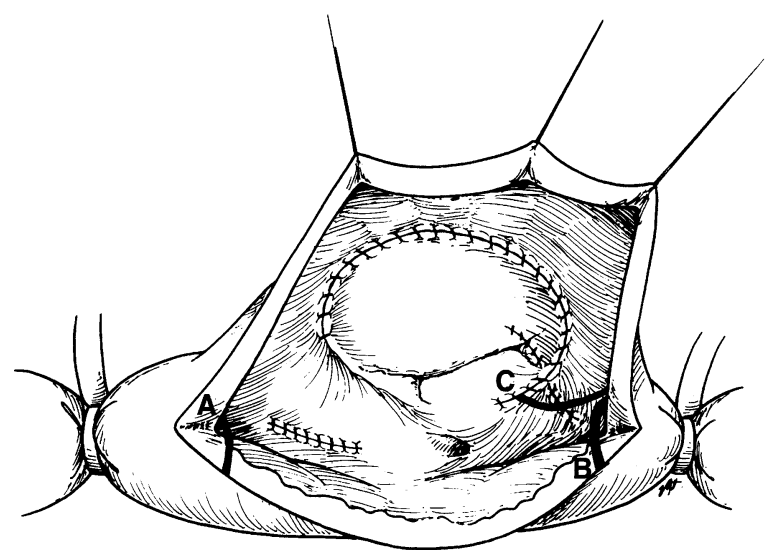

Figure 5. Lesions for radiofrequency ablation. A, Superior vena cava to atrial incision; B, IVC to atrial incision; C, IVC-tricuspid annulus ("isthmus block"). Reprinted from the Journal of the American College of Cardiology, Vol 17, Quaegebeur JM, Sreeram N, Fraser AG, Bogers AJ, Stumper OF, Hess J, et al. Surgery for Ebstein's anomaly: the clinical and echocardiographic evaluation of a new technique, $p$ 722-8, copyright 1991, with permission from "The American College of Cardiology Foundation."

Intraoperative Radiofrequency Ablation

In 3 patients with documented supraventricular arrhythmias preoperatively, an intraoperative radiofrequency ablation procedure (modified right-sided maze) was performed using an RF Cobra (Boston Scientific, EP Technologies, San Jose, Calif) probe. In these instances, radiofrequency lesions were created in an effort to disrupt aberrant pathways (1) between the superior vena cava and the atrial incision, (2) between the inferior vena cava (IVC) and the 
TABLE 1. Demographics of the study cohort

\begin{tabular}{|c|c|c|c|c|c|}
\hline Patient & Age (y) & Indication & Associated lesions & Follow-up (y) & CTR \\
\hline 1 & $2 \mathrm{mo}$ & Hypoxia, CHF & PFO & 3 & 0.81 \\
\hline 2 & $6 \mathrm{mo}$ & Cyanosis & ASD & 6.1 & 0.91 \\
\hline 3 & $11 \mathrm{mo}$ & Dyspnea, SVT & ASD & 1.7 & 0.71 \\
\hline 4 & 1.6 & Cyanosis & ASD & $\mathrm{N} / \mathrm{A}$ & 0.64 \\
\hline 5 & 2.7 & Asymptomatic (significant RA/RV dilatation) & ASD, VSD & 0.1 & 0.85 \\
\hline 6 & 3.7 & Hypoxia, cyanosis & PFO, VSD & 4.9 & 0.61 \\
\hline 7 & 3.9 & Cyanosis & & N/A & 0.75 \\
\hline 8 & 4.2 & Asymptomatic (significant RA/RV dilatation) & ASD, VSD & 0.7 & 0.57 \\
\hline 9 & 5.0 & Poor exercise tolerance & ASD & $\mathrm{N} / \mathrm{A}$ & 0.71 \\
\hline 10 & 5.4 & Poor exercise tolerance, cyanosis & ASD, VSD & 3.8 & 0.69 \\
\hline 11 & 5.4 & Hypoxia, cyanosis with exercise & ASD & 3 & 0.73 \\
\hline 12 & 6.4 & Poor exercise tolerance, syncope & ASD & 0.9 & 0.7 \\
\hline 13 & 8.2 & Palpitations, CHF & PFO & 9.6 & 0.68 \\
\hline 14 & 8.2 & Poor exercise tolerance, cyanosis & PFO & 4.2 & $\mathrm{~N} / \mathrm{A}$ \\
\hline 15 & 8.9 & $\mathrm{CHF}$ & ASD & 10.9 & $\mathrm{~N} / \mathrm{A}$ \\
\hline 16 & 9.7 & CHF & MR, ASD & 1.6 & 0.71 \\
\hline 17 & 11.9 & Poor exercise tolerance & ASD & 0.8 & 0.53 \\
\hline 18 & 13.4 & Poor exercise tolerance & PFO & 6.9 & 0.65 \\
\hline 19 & 13.8 & Decreasing exercise tolerance, cyanosis & ASD & $\mathrm{N} / \mathrm{A}$ & 0.63 \\
\hline 20 & 27.4 & Cyanosis with exercise, palpitations & ASD & 8.7 & 0.39 \\
\hline 21 & 30.5 & Dyspnea on exertion (mild) & PFO & N/A & 0.63 \\
\hline 22 & 45.2 & Decreased exercise tolerance, SVT & ASD & 0.1 & 0.8 \\
\hline 23 & 45.7 & Dyspnea on exertion, cyanosis & ASD & 6 & 0.57 \\
\hline 24 & 46.3 & Dyspnea on exertion & ASD & 8.4 & $\mathrm{~N} / \mathrm{A}$ \\
\hline 25 & 46.8 & Syncope with exercise, atrial fibrillation & PFO & 1 & 0.65 \\
\hline
\end{tabular}

SVT, Supraventricular tachycardia; CHF, congestive heart failure; $P F O$, patent foramen ovale; $A S D$, atrial septal defect; VSD, ventricular septal defect; $M R$, mitral regurgitation; $R A$, right atrium; $R V$, right ventricle; $N / A$, not available; $C T R$, cardiothoracic ratio.

atrial incision, and (3) between the IVC and the tricuspid annulus. In all cases, particular attention was made to avoid fibers of the conduction system, especially during creation of the so-called isthmus block (IVC-tricuspid annulus) (Figure 5).

\section{Antiarrhythmic Protocol}

Study patients were not subject to a standardized preoperative or postoperative antiarrhythmic medication protocol. Those 3 patients who underwent radiofrequency ablation were maintained on intravenous amiodarone, which was later converted to oral amiodarone; this regimen was maintained for the first 3 postoperative months and subsequently discontinued. Those patients on antiarrhythmic regimens preoperatively had their medications reinstated postoperatively.

\section{Results}

Of the 36 patients undergoing operation during the study period with the diagnosis of Ebstein anomaly, 25 (19 children and 6 adults) underwent primary repair. Eleven patients (with concomitant complex lesions) underwent other procedures, including staging to a single ventricle repair (6), orthotopic heart transplantation (1), and other complex procedures (4).

The 25 patients undergoing primary repair constituted the study cohort. The average age of the cohort was $14.2 \pm$ 15.9 years, and the average follow-up was $4.1 \pm 3.4$ years (median 3.4 years). The average preoperative cardiothoracic ratio was $0.68 \pm 0.11$ (median 0.69). Patient demographics are summarized in Table 1. Additional procedures are listed in Table 2. Five patients $(20 \%)$ demonstrated atrioventricular dissociation perioperatively; however, only 2 patients $(8 \%)$ later required permanent pacemaker insertion (one on postoperative day 10 , the other 5 years postoperatively). The remainder of the cohort maintained normal sinus rhythm throughout the perioperative and postoperative periods.

The results of preoperative, perioperative (before discharge), and postoperative echocardiograms are noted in Table 3. The results listed in italics represent echocardiograms for which official reports, but not actual studies, were available for the current evaluation. As demonstrated, the majority of patients had qualitatively normal biventricular function preoperatively. However, it often can be difficult to estimate right ventricular function in the presence of severe tricuspid regurgitation and a large atrialized ventricle. Most patients had moderate or severe tricuspid regurgitation, which in $35 \%$ remained moderate post-repair; unfortunately, intraoperative echocardiograms were inconsistently available for review. Reports of echocardiograms obtained later postoperatively demonstrated an improvement in tricuspid regurgitation for many of these patients. Ebstein 
TABLE 2. Operations and complications in the study cohort

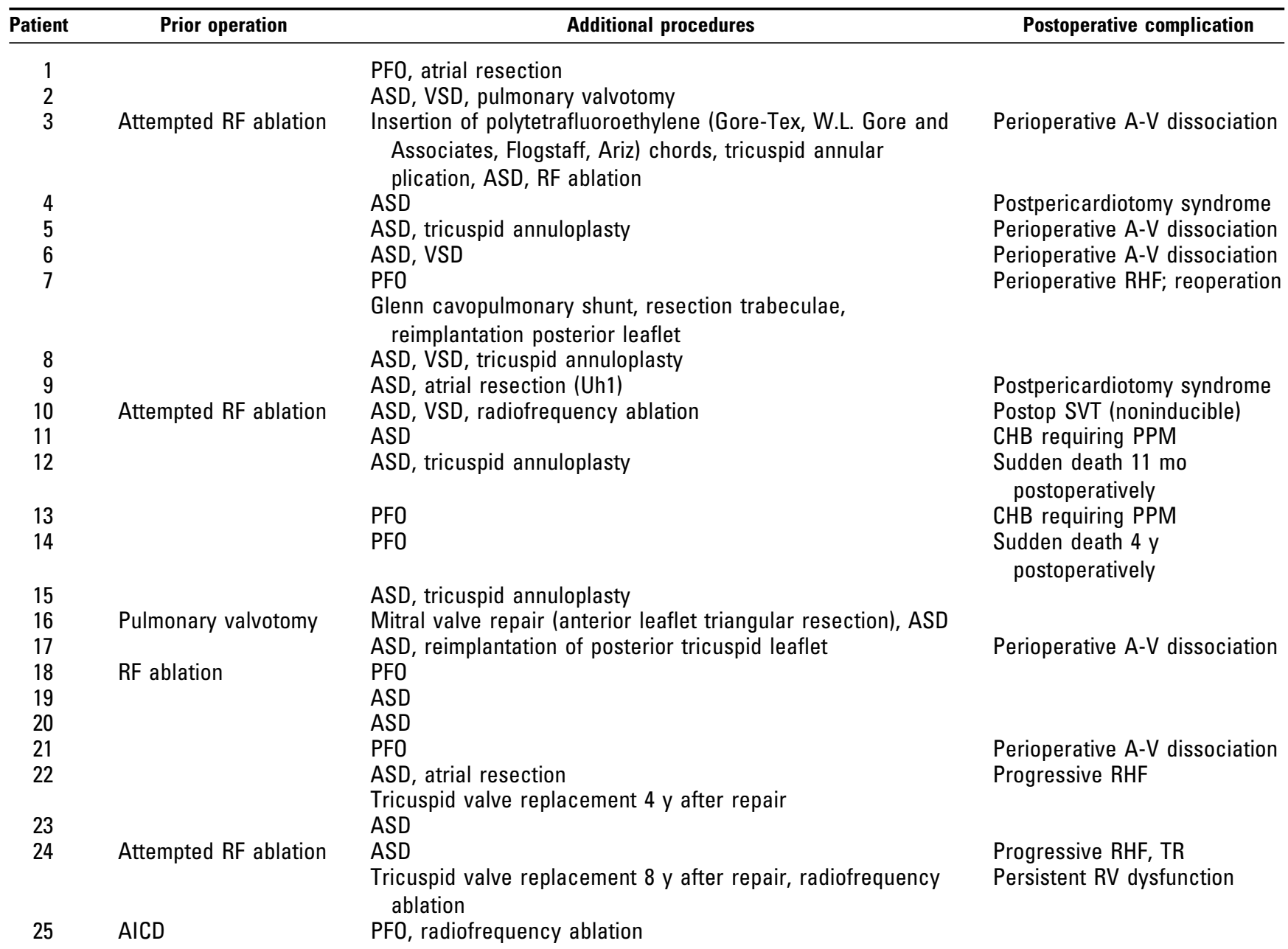

SVT, Supraventricular tachycardia; $P F O$, patent foramen ovale; $A S D$, atrial septal defect; $V S D$, ventricular septal defect; $R F$, radiofrequency; $T R$, tricuspid regurgitation; $C H B$, complete heart block; $P P M$, permanent pacemaker; $R H F$, right heart failure; $R V$, right ventricular; $A I C D$, automatic implantable cardiovascular defibrillator; $A-V$, arteriovenous.

repair rendered the tricuspid apparatus largely normal insofar as only mild annular displacement was present in the majority of patients postoperatively. Of note, although most patients demonstrated normal preoperative right ventricular function, one quarter demonstrated decreased right ventricular ejection fraction perioperatively (the majority of these cases resolved later postoperatively).

Three patients required reoperation related to their Ebstein repair. One child returned to the operating room 3 days postoperatively for conversion to a Glenn cavopulmonary shunt after progressive, severe right ventricular failure with tricuspid regurgitation and subsequent increased right atrial pressure developed. At reoperation, additional trabeculations to the right ventricular free wall were resected, and the papillary muscle was reimplanted closer to the tricuspid annulus to allow for better leaflet coaptation. Two adults ultimately required tricuspid valve replacement, 4 and 8 years postoperatively, for progressive right-sided circulatory failure and dyspnea. In both cases, the prior Ebstein repair was noted to have broken down because of degeneration of the leaflet tissues (and not because of further annular dilatation).

Two children died suddenly 11 months and 4 years postoperatively. Neither had displayed arrhythmic foci perioperatively or undergone prior ablative procedures. The child who died 4 years postoperatively had not demonstrated any arrhythmias on a Holter investigation the month before. Neither patient underwent postmortem anatomic analysis. Five patients were lost to follow-up.

Three patients underwent adjunctive radiofrequency ablation for preoperative intractable supraventricular tachycardias. At 6-month and 1-year follow-ups, none of these 
patients had experienced further arrhythmic events or were maintained on oral antiarrhythmic medications.

\section{Discussion}

Ebstein anomaly represents an unusual congenital cardiac lesion with extremely variable clinical presentation. The characteristic anatomic feature is that of downward displacement and adherence of dysplastic septal and posterior tricuspid leaflets into the right ventricle, thereby dividing the ventricle into a so-called atrialized chamber and a functionally reduced right ventricle. ${ }^{1-4}$ The large anterior leaflet of the tricuspid valve may demonstrate restricted mobility because of muscular trabeculations to the right ventricular free wall. Whereas early repairs sought primarily to address the essential problem of tricuspid regurgitation, later techniques have each concentrated on reconstruction of these essential deformities: liberation of the anterior leaflet from its adhesions, exclusion or reduction of the atrialized ventricle, reinstitution of valvular integrity and competency by reattaching the anterior leaflet to the new annulus, and remodeling of the tricuspid valve annulus and inflow portion of the right ventricle. ${ }^{8-17}$

Despite these similarities, significant contention remains regarding the specific components of repair. Some have maintained that exclusion of the atrialized ventricle may be unnecessary, and that the most important part of repair is the construction of a competent tricuspid valve. ${ }^{15}$ In contrast, others have suggested the need for cavopulmonary shunt procedures to ameliorate right-sided volume overload, instead asserting that ventricular unloading may contribute favorably to ventricular remodeling and reduce the need for more complicated valve repair techniques. ${ }^{13}$ In the case of neonates with Ebstein anomaly, only recently have reports of successful outcomes with complete repair challenged the notion of functional univentricular palliation as the only therapeutic option for these children. ${ }^{18-20}$

Clearly, however, improved outcomes with repair during the past 2 decades have decreased the threshold for operative intervention, especially given the likely natural progression toward a deterioration of right-sided heart function and tricuspid regurgitation, the potential development of arrhythmogenic foci, and poor long-term outcomes. ${ }^{1,21,22}$ Our current indications for operation include progressive development of cyanosis or symptomatic dyspnea and increasing right ventricular size as assessed by echocardiography and radiographic cardiothoracic ratio. In light of the improved results with repair, we have begun to view the progressive decline in right ventricular function (especially in adults) and development of significant intractable arrhythmias as encouragement toward operative intervention.

As many as 79\% of patients with Ebstein anomaly have demonstrated supraventricular or ventricular arrhythmias, and sudden death has been reported to occur in up to $20 \%$ of these patients. ${ }^{23,24}$ Although the pathologic anatomy in Ebstein anomaly is thought to provide an ideal substrate for aberrant conductive pathways, the appropriate treatment for their ablation remains unclear. The deaths of the 2 patients in our cohort occurred 11 months and 4 years post-repair, but the deaths were both sudden in nature, and in the absence of evidence to the contrary must be considered arrhythmic in cause.

We undertook the current study to evaluate our mediumterm outcomes with repair of Ebstein anomaly at a single institution. Our technique for repair has not varied substantially during the 12-year period or been modified specifically with regard to patient age. The findings of this study are notable for several key observations.

First, since the initial report of our experience with this repair technique, various alterations have taken place. We maintain that the vertical plication of the right ventricle restores the normal inlet portion of the right ventricle, reduces the tricuspid valve annulus, and supports the subvalvar apparatus. In addition, the plication itself likely helps to maintain a more normal ventricular geometry and thereby promotes remodeling. Unlike the Danielson technique, in which a monocusp valve is created, the current repair creates a bileaflet valve (at least when a posterior leaflet, albeit morphologically abnormal, is present). We have on occasion used an atrial reduction procedure, especially in cases with Uhl disease; however, in general, we do not consider atrial reduction a necessary part of the procedure. Finally, annular reinforcing sutures or artificial polytetrafluoroethylene (Gore-Tex) chords were required in only select cases.

Second, in the majority of children in our cohort, repair of Ebstein anomaly has excellent functional outcomes despite residual postoperative tricuspid regurgitation by echocardiogram. Although many patients in the study presented with symptoms of cyanosis $(8,42 \%)$, progressive exercise intolerance $(6,31 \%)$, and severe tricuspid regurgitation (10, $40 \%$ ), and demonstrated little tricuspid regurgitation intraoperatively post-repair, 10 patients $(40 \%)$ later revealed moderate-to-severe tricuspid regurgitation on echocardiogram before hospital discharge. Notably, all had normal biventricular function documented preoperatively, but 9 patients $(36 \%)$ demonstrated some decrement in their right ventricular function on perioperative echocardiogram.

The relative prevalence of tricuspid regurgitation perioperatively may represent a poor predictor of long-term results owing to temporary postoperative tricuspid papillary muscle dysfunction and impairment in right ventricular contractility. This is substantiated in part by those echocardiograms obtained late postoperatively that demonstrate improvement in many of these patients. In addition, the morphology of the tricuspid jet measured is significantly different postoperatively; whereas the jet is quite broad preoperatively, after repair it tends to be narrower and 
TABLE 3. Preoperative, perioperative, and late postoperative echocardiographic results in the study cohort

\begin{tabular}{|c|c|c|c|c|c|}
\hline \multirow[b]{2}{*}{ Patient } & \multicolumn{5}{|c|}{ Preoperative } \\
\hline & RVEF & TR & ESS & Anterior tethering & LVEF \\
\hline 1 & Normal & Severe & $B$ & Mild & Normal \\
\hline 2 & Normal & Moderate & C & Mild & Normal \\
\hline 3 & Normal & Severe & C & Moderate & Normal \\
\hline 4 & Normal & Moderate & B & Moderate & Normal \\
\hline 5 & Normal & Moderate & B & Mild & Normal \\
\hline 6 & Normal & Moderate & B & Mild & Normal \\
\hline 7 & Normal & Severe & $\mathrm{D}$ & Moderate-severe & Normal \\
\hline \multicolumn{6}{|l|}{ (reop) } \\
\hline 8 & Normal & Mild & A & Mild & Normal \\
\hline 9 & Normal & Moderate & & & Normal \\
\hline 10 & Normal & Severe & $D$ & Moderate-severe & Normal \\
\hline 11 & Normal & Severe & C & Moderate & Normal \\
\hline 12 & Normal & Severe & D & Moderate-severe & Normal \\
\hline 13 & Mildly decreased & Moderate & $\mathrm{B}$ & Mild & Normal \\
\hline 14 & Normal & Moderate & B & Mild-moderate & Normal \\
\hline 15 & Normal & Mild & $\mathrm{B}$ & Mild-moderate & Normal \\
\hline 16 & Normal & Severe & $\mathrm{B}$ & Mild & Normal \\
\hline 17 & Normal & Severe & C & Mild & Normal \\
\hline 18 & Normal & Mild & B & Mild & Normal \\
\hline 19 & Normal & Severe & & Moderate-severe & Normal \\
\hline 20 & Normal & Moderate & C & Moderate & Normal \\
\hline 21 & Normal & Severe & $\mathrm{B}$ & Mild & Normal \\
\hline 22 & Normal & Moderate & C & Moderate & Normal \\
\hline 23 & & & $\mathrm{~N} / \mathrm{A}$ & & \\
\hline 24 & Normal & Severe & C & Moderate & Normal \\
\hline 25 & Normal & Severe & $A$ & Mild & Normal \\
\hline
\end{tabular}

ESS, Ebstein Severity Score; TR, tricuspid regurgitation; RVEF, right ventricular ejection fraction; $L V E F$, left ventricular ejection fraction; $N / A$, not available. *Date of study.

located just at the level of the junction between the transposed posterior and septal leaflets. The reversal of flow in the hepatic veins was inconsistently studied; thus, it could not be used as a criterion, but it would be helpful in future analyses. However, it is unclear whether this degree of regurgitation is ultimately of true functional import.

Indeed, 18 children (95\%) had significant improvement in their functional exercise capacity at $3.7 \pm 3.4$ years follow-up, with no exercise limitations; only 1 child remains limited by asthma. The reason for this improvement in exercise capacity in children despite residual tricuspid regurgitation is unknown. Although conjectural, this is likely because of a relative reduction in right ventricular volume load (and improvement in contractility) post-repair, in addition to the presumed annular and ventricular plasticity in children that may not be shared by their adult counterparts. We have demonstrated the utility of echocardiographic acceleration variables in the aorta as accurate estimates of right ventricular contractility. ${ }^{17}$ Unfortunately, such variables were incompletely examined by outside echocardiographers to be used consistently as postoperative measures in the current study.

In contrast, although 5 adults (83\%) demonstrated comparable improvement in functional capacity, 2 adults (33\%) required tricuspid valve replacement 4 and 8 years after repair. Indeed, 1 of these patients remains ultimately limited by poor right ventricular function despite valve replacement (albeit likely related to a concomitant pulmonary embolus). Both adult patients who required valve replacement also demonstrated complete breakdown of their prior repair primarily because of valve leaflet degeneration (and not because of progressive annular dilatation). In adults, this impaired leaflet integrity compounds the decreased plasticity of the tricuspid annulus (and likely tension with repair). In addition, long-standing right ventricular fibrosis and reduced ventricular plasticity both impact negatively on postoperative ventricular remodeling. Taken together, these factors likely contribute significantly to problems with longterm repair durability in adults. These results must also be viewed in light of reports by the Mayo Clinic group demonstrating good long-term durability of bioprosthetic tricuspid valves inserted for Ebstein anomaly. ${ }^{25}$

Third, since the introduction of intraoperative radiofrequency ablation techniques to our institution in 2000, we have been more liberal in their use for congenital heart surgery. As noted previously, arrhythmias represent a substantial source of morbidity and mortality for patients with Ebstein anomaly, even many years postoperatively. These 
TABLE 3. Continued

\begin{tabular}{|c|c|c|c|c|c|c|c|}
\hline \multicolumn{4}{|c|}{ Immediate postoperative } & \multicolumn{4}{|c|}{ Late postoperative } \\
\hline RVEF & TR & Annular displacement & LVEF & Years postop* & RVEF & TR & LVEF \\
\hline Decreased & Mild & Mild & Normal & 3.0 & Normal & Mild & Normal \\
\hline Normal & Mild & Moderate & Normal & 6.1 & Normal & Mild & Normal \\
\hline Decreased & $\begin{array}{c}\text { Moderate-severe } \\
\text { N/A }\end{array}$ & Mild & Normal & 0.1 & Normal & Moderate & Normal \\
\hline Normal & Moderate & Mild & Normal & 0.1 & Normal & Mild & Normal \\
\hline Normal & Moderate & Moderate & Normal & 4.9 & Normal & Severe & Normal \\
\hline Decreased & Severe & Moderate & Normal & & Reoperated & & \\
\hline Decreased & Mild & Mild & Normal & \multicolumn{4}{|c|}{$N / A$} \\
\hline Normal & $\begin{array}{c}\text { Mild-moderate } \\
\text { N/A }\end{array}$ & Mild & Normal & & Normal & Mild & Normal \\
\hline Normal & Moderate & Mild-moderate & Normal & 0.9 & Normal & Moderate & Normal \\
\hline Decreased & Severe & Moderate & Normal & 2.5 & Normal & Moderate & Normal \\
\hline Normal & Severe & Mild & Normal & Died & & & \\
\hline Normal & $\begin{array}{c}\text { Mild-moderate } \\
\text { N/A }\end{array}$ & $\begin{array}{l}\text { Mild } \\
3.1\end{array}$ & $\begin{array}{l}\text { Normal } \\
\text { Normal }\end{array}$ & $\begin{array}{l}9.5 \\
\text { Trace }\end{array}$ & $\begin{array}{l}\text { Normal } \\
\text { Normal }\end{array}$ & Mild & Normal \\
\hline Normal & Moderate & Mild & Normal & \multicolumn{4}{|c|}{ N/A } \\
\hline Normal & Moderate & Mild & Normal & 1.6 & Normal & Moderate & Normal \\
\hline Normal & Severe & Mild & Normal & 0.8 & Normal & Moderate & Normal \\
\hline Decreased & None $\mathrm{N} / \mathrm{A}$ & Mild & Normal & 5.0 & Normal & None & Normal \\
\hline Normal & Mild & Mild & Normal & \multicolumn{4}{|c|}{ N/A } \\
\hline Normal & Mild & Mild-moderate & Normal & 2.0 & Normal & Moderate & Normal \\
\hline Normal & Severe & Moderate & Normal & 0.0 & Normal & Replaced & Normal \\
\hline Normal & Mild & Mild & Normal & \multicolumn{4}{|c|}{ N/A } \\
\hline Decreased & Severe & Moderate & Normal & 0.1 & Decreased & Replaced & Normal \\
\hline Decreased & Moderate & Mild & Normal & 0.0 & Decreased & Mild & Normal \\
\hline
\end{tabular}

aberrant pathways can be more difficult to ablate percutaneously than in patients without Ebstein anomaly.,6

The addition of intraoperative radiofrequency ablative lesions adds little operative time to the overall repair and requires no further exposure techniques. Some would argue that the repair by its nature likely disrupts most aberrant pathways (especially those within the atrialized ventricle that is either excised or imbricated) and have reported a resolution in supraventricular tachycardia in up to $30 \%$ of patients undergoing Ebstein repair alone., ${ }^{5,23}$ In addition, when successful, repair should further reduce the ultimate arrhythmogenic nidus of right atrial distension. However, for those patients who demonstrate preoperative myocardial irritability-especially those in whom percutaneous ablative attempts were unsuccessful-intraoperative ablation represents an important adjunct toward improved long-term outcomes. All of our patients who underwent intraoperative ablation are free of significant arrhythmias 1 year postoperatively and do not require antiarrhythmic medications.

Finally, these findings, when viewed in light of the encouraging medium-term outcomes, indicate that earlier operative intervention in Ebstein anomaly should be considered before the development of significant deterioration in right-sided heart function. Adult patients with advanced disease may not demonstrate comparable prolonged durability to their repair owing to poor leaflet integrity, large annuli, and reduced ventricular plasticity; however, they may still benefit significantly from valve replacement. As has been suggested by others, the presence of arrhythmias themselves should likely be considered a relative indication for operative intervention, both for restoration of ventricular dynamics and potential ablation of future aberrant conduction pathways.

\section{Limitations}

Several limitations must be highlighted in the current study. First, by its nature this evaluation is subject to the restrictions of a retrospective study. Follow-up, in particular, was difficult to obtain in many patients who had moved far from the medical center or who had undergone repair in the distant past; original echocardiograms more than 10 years old were difficult to obtain and often of poor quality. Second, only a select group of patients underwent exercise testing either before or after repair; thus only subjective conclusions could be inferred regarding exercise tolerance and improvement from postoperative out-patient evaluations and subjective telephone interviews. Finally, because many of the patients were referred from a variety of con- 
sultants, the regularity with which follow-up echocardiograms were obtained and the details of their examination were quite variable. Future studies evaluating the long-term durability of repair and its effect on overall exercise tolerance will clearly require standardization in postoperative assessments.

\section{References}

1. Mair DD. Ebstein's anomaly: natural history and management. $J$ Am Coll Cardiol. 1992;19:1047-8.

2. Attie F, Rosas M, Rijlaarsdam M, Alfonson B, Zabal C, Kuri J, et al. The adult patient with Ebstein anomaly: outcome in 72 unoperated patients. Medicine (Baltimore). 2000;79:27-36.

3. Celermajer DS, Bull C, Till JA, Cullen S, Vassillikos V, Sullivan ID, et al. Ebstein's anomaly: presentation and outcome from fetus to adult. J Am Coll Cardiol. 1994;23:170-6.

4. Spitaels SEC. Ebstein's anomaly of the tricuspid valve complexities and strategies. Cardiol Clin. 2002;20:431-9.

5. Lo H, Lin F, Jong Y, Tseng Y, Wu T. Ebstein's anomaly with ventricular tachycardia: evidence for the arrhythmogenic role of the atrialized ventricle. Am Heart J. 1989;117:959-62.

6. Cappato R, Schlüter M, Weiss C, Antz M, Kopschyk DH, Hofman T, et al. Radiofrequency current catheter ablation of accessory atrioventricular pathways in Ebstein's anomaly. Circulation. 1996;94:376-83.

7. Oh J, Holmes DR, Hayes DL, Porter CJ, Danielson GK. Cardiac arrhythmias in patients with surgical repair of Ebstein's anomaly. J Am Coll Cardiol. 1985;6:1351-7.

8. DiRusso GB, Gaynor JW. Ebstein's anomaly: indications for repair and surgical technique. Semin Thorac Cardiovasc Surg Pediatr Card Surg Аnпи. 1999;2:35-50.

9. Carpentier A, Chauvaud S, Macé L, Relland J, Mihaileanu S, Marino JP, et al. A new reconstructive operation for Ebstein's anomaly of the tricuspid valve. J Thorac Cardiovasc Surg. 1988;96:92-101.

10. Danielson GK, Driscoll DJ, Mair DD, Warnes CA, Oliver WC. Operative treatment of Ebstein's anomaly. $J$ Thorac Cardiovasc Surg. 1992;104:1195-202.

11. Kupilik N, Simon P, Moidl R, Wollenek G, Marx M, Wolner E, et al. Valve-preserving treatment of Ebstein's anomaly: perioperative and follow-up results. Thorac Cardiovasc Surg. 1999;47:229-34.

12. Mair DD, Seward JB, Driscoll DJ, Danielson GK. Surgical repair of Ebstein's anomaly: selection of patients and early and late operative results. Circulation. 1985;72(Suppl II):II70-6.

13. Marianeschi SM, McElhinney DB, Reddy VM, Silverman NH, Hanley FL. Alternative approach to the repair of Ebstein's malformation: intracardiac repair with ventricular unloading. Ann Thorac Surg. 1998; 66:1546-50.

14. Wu Q, Huang Z. Anatomic correction of Ebstein anomaly. J Thorac Cardiovasc Surg. 2001;122:1237-8.

15. Augustin N, Schmidt-Habelmann P, Wottke M, Meisner H, Sebening F. Results after surgical repair of Ebstein's anomaly. Ann Thorac Surg. 1997;63:1650-6.

16. Hetzer R, Nagdyman N, Ewert P, Weng YG, Alexi-Meskhisvilli V, Berger F, et al. A modified repair technique for tricuspid incompetence in Ebstein's anomaly. J Thorac Cardiovasc Surg. 1998;115:857-68.

17. Quaegebeur JM, Sreeram N, Fraser AG, Bogers AJJC, Stümper OFW, Hess J, et al. Surgery for Ebstein's anomaly: the clinical and echocardiographic evaluation of a new technique. J Am Coll Cardiol. 1991; 17:722-8.

18. Knott-Craig CJ, Overholt ED, Ward KE, Razook JD. Neonatal repair of Ebstein's anomaly: indications, surgical technique, and mediumterm follow-up. Ann Thorac Surg. 2000;69:1505-10.

19. Knott-Craig CJ, Overhotld ED, Ward KE, Ringewald JM, Baker SS, Razook JD. Repair of Ebstein's anomaly in the symptomatic neonate: an evolution of technique with 7-year follow-up. Ann Thorac Surg. 2002;73:1786-93.

20. Starnes VA, Pitlick PT, Berstein D, Griffin ML, Choy M, Shumway NE. Ebstein's anomaly appearing in the neonate. J Thorac Cardiovasc Surg. 1991;101:1082-7.
21. Barber G, Danielson GK, Heise CT, Driscoll DJ. Cardiorespiratory response to exercise in Ebstein's anomaly. Am J Cardiol. 1985;56: 509-14.

22. Driscoll DJ, Mottram CD, Danielson GK. Spectrum of exercise intolerance in 45 patients with Ebstein's anomaly and observation on exercise tolerance in 11 patients after surgical repair. $J$ Am Coll Cardiol. 1988;11:831-6.

23. Chauvaud SM, Brancaccio G, Carpentier AF. Cardiac arrhythmia in patients undergoing surgical repair of Ebstein's anomaly. Ann Thorac Surg. 2001;71:1547-52.

24. Misaki T, Watanabe G, Iwa T, Watanabe Y, Mukai K, Takahashi M, et al. Surgical treatment of patients with Wolf-Parkinson-White syndrome and associated Ebstein's anomaly. J Thorac Cardiovasc Surg. 1995;110:1702-7.

25. Kiziltan HT, Theodoro DA, Warnes CA, O'Leary PW, Anderson BJ, Danielson GK. Late results of bioprosthetic tricuspid valve replacement in Ebstein's anomaly. Ann Thorac Surg. 1998;66:1539-45.

\section{Discussion}

Dr Joseph A. Dearani (Rochester, Minn). I appreciate the opportunity to discuss the presentation by Dr Chen of the results of surgical treatment of Ebstein anomaly performed by him and his colleagues at Columbia University. I did not have the opportunity to read the manuscript in advance, so my comments will be directed toward the presentation. The major question in my mind is the significance of accepting significant residual tricuspid regurgitation at the end of the procedure in a patient with Ebstein anomaly. You have tried to demonstrate in your review that significant tricuspid regurgitation is better tolerated in the child compared with the adult.

Our approach toward and philosophy of surgical treatment of Ebstein anomaly are different. Our objective with operation is to eliminate tricuspid regurgitation, close the atrial septal defect, correct other abnormalities if present, and perform an antiarrhythmia procedure as indicated. We accept mild, and moderate at most, residual tricuspid regurgitation at the end of the procedure. If moderately severe or severe tricuspid regurgitation is present, we then proceed with porcine bioprosthetic tricuspid valve replacement. We believe that the function of the myopathic right ventricle present in all patients with Ebstein anomaly is preserved better in the long term in the absence of tricuspid regurgitation.

Our technique of repair has evolved during the last 3 decades. We have performed operations in approximately 500 patients with Ebstein anomaly at the Mayo Clinic, and approximately half underwent valve repair. Currently, our technique involves moving the major papillary muscle(s) toward the ventricular septum and performing maneuvers that progressively bring the leading edge of the anterior leaflet closer to the ventricular septum for coaptation. The repair is performed at the level that the valve exists in the right ventricle. Both transverse and vertical plications have been performed and are now reserved for only the severely dilated hearts. Careful attention to the preservation of the major coronary arteries and their branches is critically important during these plication maneuvers.

What do you use as a guide for the indications for reoperation if many of your patients already have grade III tricuspid regurgitation?

You described your technique of repair. Was this technique applied in all of the patients or have you developed other modifications that were used in some of these patients? 
I congratulate the authors with their management of a challenging group of patients. I would appreciate your thoughts on the long-term effect of accepting significant tricuspid regurgitation and its volume load on the myopathic ventricle present in Ebstein anomaly and your criteria for reoperation.

Dr Chen. You correctly identified that one of the big surprises of our analysis was the reasonable amount of postoperative tricuspid regurgitation we found with our immediate postoperative and sometimes late postoperative studies.

I think what this has also reemphasized to us is the necessity of having a highly skilled echocardiographer in the operating room to assess the morphology of the tricuspid regurgitation jet, which itself can be quite misleading.

Clearly, when we look at studies sent from outside cardiologists of children undergoing repair, there are many overestimates of tricuspid regurgitation, based on the finding that a narrow jet can look quite severe. In fact, when compared with the previous study (in which the tricuspid regurgitation jet was broad), this narrow jet may have less of a severe hemodynamic consequence.

In answer to your question about when we would consider leaving the tricuspid regurgitation, I think a lot of it has to do with how severe the Carpentier grade is preoperatively in terms of how likely we think the repair itself will be durable. I think anyone who has a Carpentier D grade will be less likely to either tolerate the severe tricuspid regurgitation or have an excellent outcome with repair.

What is interesting, though, is that among these children, the relative right ventricular plasticity seems to protect them from the immediate effects of tricuspid regurgitation in the perioperative period. Once the myocardial function improved, they also seemed to improve symptomatically.

With regard to your second question about variations in our repair, I think these are basically our principles of repair. The adjunctive procedures, the De Vega annuloplasty, the additional polytetrafluoroethylene (Gore-Tex) cord, and so forth are variations on the theme, but for the most part, the repair has remained the same.

Dr Florentino J. Vargas (Buenos Aires, Argentina). Back in 1986, during my year as Graham Fellow of The American Association for Thoracic Surgery, I had the opportunity to study the Ebstein specimens in the pathology laboratory at Boston Children's Hospital. Two years later, a technique was devised. This included a vertical plicature performed simultaneously with the annuloplasty using a single suture that brought the anterior-posterior commissure together with the septal leaflet or its remnant. The cul-de-sac thus formed was plicated using the same suture. No translocation or mobilization of the annulus was performed at all, and the plicated tissue therefore remained within the right atrium. We performed this procedure in our first patient in 1989 and have performed it in 14 patients so far. This series and data were published a few years ago. At 6 years of follow-up, we are seeing in our patients a mild or moderate degree of tricuspid regurgitation and an overall excellent functional result. It is interesting for us that the remaining functional right ventricle seemed to grow quite well with age, and we are now trying to figure out how we can measure and do objective measurements of this growing ventricle.

I have 2 questions regarding your presentation. First of all, for the cases in which you considered it necessary to add an additional bidirectional Glenn as part of the repair, which parameters will you take to make the decision, and when will you make the decision? I mean before, during, or after the pump?

The second question regards the vertical plicature itself. In the technique you used, a vertical plicature is used. Because you translocate the tricuspid annulus, this vertical plicature is included within the future right ventricular cavity. How does a repair of that abnormal restored part of the anatomy of the right ventricle compare with the functional viewpoint in your follow-up findings?

Dr Chen. There is certainly a great deal of contention with regard to the plication of the right ventricular cavity.

I concur with the group who implies that the atrialized ventricle may not be wholly functional beforehand and therefore will not contribute much to right ventricle contractility.

Excluding it certainly did not negatively affect the right ventricular contractility. In fact, in all of the postoperative studies, right ventricular function improved with exclusion. It may be that excluding the paradoxic region has salutary effects on contractility.

Dr Quaegebeur may actually be the best person to comment on the Glenn procedure, but we performed a bidirectional Glenn at the time of reoperation in only 1 patient to reduce the volume load while still pursuing a revision of the repair, as opposed to a valve replacement.

Dr J. Quaegebeur (New York, NY). We would not perform a Glenn in a pediatric age group of children. The results might not be exactly the same as in an adult group in whom using a Glenn as part of the operation is probably more frequently performed.

So we would not perform it as our primary intention, and this particular child had a poor result. Together with the revision, we performed the Glenn, which was perhaps not completely necessary.

In regard to the plication, we tried to exclude the nonfunctional part of the right ventricle. Although in this particular group we did not use these measurements, in a previous group we had used Doppler velocity studies, which is some sort of a surrogate for right ventricular function.

In the majority of patients, the velocity of blood flow from the tricuspid annulus across the right ventricle into the pulmonary artery is increased after excluding that atrialized portion of the right ventricle. We believe it is an important part of the repair.

Dr George E. Sarris (Athens, Greece). This is a study of the numerator of the patients who had repair of Ebstein anomaly in the pediatric age group. I am wondering about the denominator, and particularly how did you decide, if that occurred at all, that perhaps some patients with the more severe forms of Ebstein anomaly, say type $\mathrm{D}$, perhaps were not suitable for repair, and what operations did you choose to do in those patients? Do you have any information on this issue?

Dr Chen. Thank you. I do not have the complete information. We excluded from this analysis approximately 10 patients with a diagnosis of Ebstein, usually with more complicated procedures that did not involve the Ebstein repair. We also excluded patients who were ultimately committed toward a single ventricle repair pathway. Any of the patients who underwent a full repair as any portion of their procedure were included in this cohort. So, unfortunately, I cannot exactly speak to the outcomes of that group of patients who did not undergo attempts at repair.

In general, we would entertain the idea of performing a repair in any patient, even those with grade D (especially children), because, in general, the results have really been quite good. 